\title{
La niña de tus ojos (1998) de Fernando Trueba : de la tradición hollywoodiense a la comedia española
}

\author{
Marianne Bloch-Robin \\ Universidad Charles de Gaulle Lille 3 \\ CECILLE Centre d'Etudes en Civilisations, Langues et Lettres Etrangères (EA 40 74)
}

Fernando Trueba dirigió su noveno largometraje La niña de tus ojos en 1998, tres años después de haber realizado Two much, una comedia de enredos rodada en inglés y en Estados Unidos, con Antonio Banderas, Melanie Griffith y Daryl Hannah como protagonistas principales. Bien se conoce el amor del realizador madrileño por los grandes directores de la edad de oro de la comedia americana ${ }^{1}$. Con Two much rendía homenaje a la Screwball comedy, reuniendo muchos de los ingredientes que hicieron su gran éxito: una sucesión de quid pro quo y de gags que se encadenaban para formar una narración linear con diálogos brillantes, ritmo vertiginoso y una historia de amor central excéntrica y desordenada en un ambiente lujoso. Esta comedia, al 90\% estadounidense, presentaba sin embargo elementos de cultura hispánica que, a veces, se integraban de manera bastante torpe y en la película. Con La niña de tus ojos, el director español vuelve a tomar en parte la senda de su película anterior Belle Époque (1992) con un enfoque hispánico y un marco espaciotemporal bastante próximo para crear una obra inspirada en un hecho real : el rodaje en 1938, en los estudios berlineses de la productora UFA $^{2}$ en la Alemania nazi, de una doble versión - en español y en alemán - de una película del director aragonés Florián Rey titulada Carmen, la de Triana con su mujer la estrella Imperio Argentina. Según Fernando Trueba, la elaboración del guión de La niña de tus ojos tardó siete años ${ }^{3}$, contando con la colaboración de cuatro personas entre las cuales podemos destacar a

\footnotetext{
${ }^{1}$ El director madrileño rindió públicamente homenaje a Billy Wilder, al que comparó con Dios, cuando se le concedió el Oscar a la mejor película de habla no inglesa en 1994 por su obra Belle Époque (1992).

${ }^{2}$ Universum film Aktien Gesellschaft.

${ }^{3}$ Mora, Miguel "Trueba considera que La niña de tus ojos es su película más difícil” El País, 4 de noviembre de 1998.

http://elpais.com/diario/1998/11/04/cultura/910134010_850215.html. Última consulta: 15/12/2013.
} 
Rafael Azcona uno de los guionistas más talentosos del cine español de la segunda mitad del siglo veinte y al realizador David Trueba, el propio hermano del director ${ }^{4}$. Entre los hechos contados por la misma Imperio Argentina o recogidos en libros, los guionistas seleccionaron elementos para sustentar su relato, conservando la anécdota principal y reciclando, a su manera, los recuerdos y la experiencia de la famosa folclórica para crear una película de ficción bastante alejada de su punto de partida. Esta independencia fue por cierto reivindicada por el director, sobre todo cuando Imperio Argentina protestó, tras visionar la película, declarando que se había falseado la realidad ${ }^{5}$.

Después de su estreno, la obra despertó considerable interés entre los especialistas de cine y numerosos artículos y estudios se escribieron sobre la película. En la mayoría de los estudios consultados, los principales ejes de análisis elegidos tocan la relación entre ficción y realidad $^{6} \mathrm{o}$ la representación tópica de España y más particularmente de Andalucía como sinécdoque de España. Fue también la ocasión de volver sobre la película de Florián Rey - calificada de españolada - y sobre la representación de la identidad nacional ${ }^{7}$. Algunos estudios reprocharon al director su visión nostálgica cuando otros afirmaron que la película integraba una crítica de la españolada como representación de la España franquista ${ }^{8}$. No obstante, si bien algunos artículos aluden a referencias cinematográficas -como el inevitable To be or not to be (1942) de Ernst Lubitschninguno se centra en la cuestión del género de la película ni en el humor que la caracteriza, que es sin embargo un elemento central en la obra. En efecto, cuando la precedente película del director revelaba debilidades a la hora de integrar elementos hispánicos, $L a$ niña de tus ojos, por el contrario aúna de manera muy harmoniosa elementos de la comedia

\footnotetext{
${ }^{4}$ También participaron los guionistas Carlos López García y Miguel Ángel Egea.

${ }^{5}$ En particular, la orientación ideológica de Macarena Granada, la protagonista de la película, una ferviente republicana, dista mucho del fervor falangista de Imperio Argentina y de la admiración que la estrella española sentía por Hitler. Ver para más precisiones el artículo de Aitor Yraola: Yraola, Aitor, " 'Misión españolista': Los camaradas Florián e Imperio con Hitler y el DR. Goebbels", www.publicacions.ub.edu/.../cinema/.../art.yraola.pdf. Última consulta, 15/12/2013.

${ }^{6}$ Rodríguez Fuentes, Carmen, "La realidad ficcionada en La niña de tus ojos de Fernando Trueba", Actas del I congreso Internacional Latina de Comunicación Social, Universidad de La Laguna, SLCS, 2009.

${ }^{7}$ Hardcastle, Anne E., "Representing Spanish identity through españolada in Fernando Trueba's The Girl of Your Dreams (La niña de tus ojos), Film Criticism, Vol. 31, №3, (Spring 2007), pp. 1537.

${ }^{8}$ Navarrete Cardero, José Luis, Historia de un género cinematográfico: La Españolada, Quiasmo Editorial, 2009, pp.270-273.
} 
hollywoodiense clásica -gracias a diversas modalidades intertextuales- y de la tradición española -incluso a través de las características típicas de la españolada-, en este caso, una tradición más bien tragicómica que mezcla los géneros, jugando con ellos, pasando constantemente de momento dramáticos o conmovedores al humor y a la risa.

La niña de tus ojos cuenta las aventuras y desventuras de un grupo de actores españoles de la zona nacional que, en 1938 -como la mayor parte de los estudios cinematográficos se encontraban en la zona republicana-, se desplaza a los estudios de la UFA en Berlín para rodar un musical titulado La niña de tus ojos. Se trata de una colaboración con la Alemania nazi que financia la película, promovida por el ministro de propaganda Joseph Goebbels. Se prevé que se rodará una versión española dirigida por el famoso director Blas Fontiveros y una versión alemana dirigida por un realizador germano incluyendo reparto alemán con excepción de la estrella, la encantadora folclórica Macarena Granada. La joven se ha aprendido los diálogos y las canciones de memoria ya que no habla el idioma. El director español -casado y con hijos- y su actriz, son amantes. Los actores españoles están encantados de dejar atrás la guerra civil y sus privaciones pero se dan cuenta enseguida de que están sumidos en otro conflicto puesto que, en cuanto llegan a Berlín, son testigos de las exacciones cometidas por la SA durante la Noche de los Cristales Rotos. Además, como los extras alemanes de la película, rubios y altos, no pueden representar a andaluces verosímiles, se utiliza a unos prisioneros judíos y gitanos cuya condición penosa descubren también los cómicos. Paralelamente, Goebbels intenta seducir a Macarena Granada que aceptó actuar en la película porque el productor español le prometió que sacaría a su padre, republicano, de la cárcel. A pesar de los esfuerzos del ministro de propaganda, Macarena, con la ayuda de Fontiveros, consigue salvarse y salvar a uno de los extras, un judío ruso, del que se enamora y con el que, con la ayuda de Fontiveros y de la mujer de Goebbels, huye en avión hacia París. El rodaje de la película se cancela y los otros miembros del elenco vuelven a España mientras un destino incierto y amenazador espera a Fontiveros que queda detenido por los nazis.

A continuación, nos proponemos analizar de qué modo se combinan en la obra las diferentes influencias de las comedias hollywoodiense y española, para crear una película muy coherente y luego veremos en qué medida esta doble influencia permite también transmitir un contenido ideológico comprometido desde el punto de vista social y político. 
El homenaje a la comedia clásica hollywoodiense se puede observar en la obra en varios niveles y modalidades: desde el guiño referencial hasta la misma narración cinematográfica pasando por la utilización de recursos cómicos inspirados por las grandes comedias de la edad de oro.

En primer lugar, se encuentran en la obra muchas referencias a los directores favoritos de Trueba: se puede destacar en particular a Ernst Lubitsch y Billy Wilder. El marco general de la película y el carácter ridículo de los nazis - de Joseph Goebbels en particular - evoca por supuesto To be or not to be y el personaje de la película apodado "Concentration Camp Erhardt", pues las dos películas elaboran una sátira del nazismo, a través de la representación grotesca de los altos dignatarios nazis presentados como imbéciles, poniendo así de relieve la crueldad y la absurdidad del régimen. Por otra parte, se encuentran en la película varios guiños referenciales que constituyen homenajes a los dos directores fetiches de Fernando Trueba. Por ejemplo, el nombre del restaurante judío en el que van a cenar los españoles, Matutchek, corresponde con el apellido del dueño de la tienda en The shop around the corner (Ernst Lubitsch, 1940). Esta alusión remite además a una película que se desarrolla en un Budapest anterior a la segunda guerra mundial en el que los judíos parecen aún integrados en la sociedad - el microcosmo de la tienda siendo una sinécdoque de ella -, con una harmonía (a pesar de las dificultades que padecen los personajes) que retrospectivamente casi se percibe como un paraíso perdido. La intertextualidad que crea la referencia intensifica pues, en la película de Trueba, la violencia de la secuencia de destrucción de las tiendas. Por otra parte, la escena en la que el protagonista de la versión alemana, Heinrich von Wemelskirch, intenta seducir a Julián Torralba el galán español al que coloca una flor en la boca, evoca también una secuencia de la famosísima Some like it hot (Billy Wilder, 1959).

Pero más allá de los guiños referenciales, Trueba y sus guionistas se apropian de estos mecanismos para crear un humor propio a partir de las referencias. Un buen ejemplo de ello es del personaje del traductor en la película - bordado como todos - que evoca poderosamente al del empleado Pirovitch en The shop around the corner : son los dos muy buenas personas, incluso valientes, pero viven aterrorizadas por la autoridad (el dueño de la tienda en la obra de Lubitsch y el riesgo de perder su empleo / los Nazis en La niña de tus ojos). A lo largo de las películas los dos personajes no dejan de repetir que no saben ni han visto nada pero luego los dos se muestran valientes cuando se trata de ayudar a los 
demás. Otros gags, tal como el saludo "a la romana" de los extras romanos de un péplum y hasta de un perro lobo o el vuelo de una mosca obstinada que viene a perturbar la grandilocuencia del discurso de Joseph Goebbels, evocan poderosamente el tratamiento del nazismo, ridiculizado en To be or not to be o en The great dictator (Charles Chaplin, 1940).

Desde el punto de vista narrativo, se puede también establecer un paralelo entre To be or not to be y La niña de tus ojos pues en los dos casos un grupo de actores que está montando una obra - de teatro en el primer caso, una película en el segundo caso- acaba resistiendo al Tercer Reich; salvando las distancias por supuesto ya que, al principio de la obra, los polacos están ya ensayando una obra satírica contra el régimen nazi cuando la trayectoria de los españoles parte de una colaboración entre la España nacionalista y la Alemania nazi.

La obra de Trueba rinde pues homenaje al cine clásico hollywoodiense en varios niveles e integra sus mecanismos cómicos o narrativos pero La niña de tus ojos hunde también sus raíces en la tradición, la cultura y en el humor españoles ya que el punto de vista del relato fílmico es claramente hispano.

En primer lugar, un potente motor dramático en la película radica en las diferencias culturales entre alemanes y españoles. A lo largo del desarrollo narrativo este desfase se explota de numerosas formas distintas a la vez visuales y lingüísticas, adoptando siempre el punto de vista español.

La anécdota del rodaje de una película ambientada en Andalucía en unos estudios berlineses da pie, en sí, a una multitud de situaciones cómicas basadas en el desfase cultural entre los dos países. La problemática de la españolada, que utiliza, deformándolos, los tópicos del país y en particular los tópicos andaluces, es una preocupación central para el realizador Blas Fontiveros y la dirección artística de la película. En efecto, todos temen la futura reacción del público español harto de los tópicos románticos reductores y orientalizantes de una España de pandereta reducida a toreros, gitanas y bandoleros. Es preciso no olvidar que desde los años veinte ${ }^{9}$ muchas películas extranjeras eran rechazadas por el público español por presentar una imagen falsa y tópica del país - fue el caso de la

\footnotetext{
${ }^{9}$ Según Marta García Carrión "[...] uno de los primeros escándalos se produjo a raíz de un film francés, La rosa de Flandes (Les opprimés, H. Roussel, 1922) película denunciada a las autoridades españolas por su contenido ofensivo e inmediatamente prohibida hasta ser censurada." García Carrión, Marta, Sin Cinematografía no hay nación. Drama et identidad nacional española en la obra de Florián Rey, Zaragoza, Institución “Fernando el Católico.”, p.49.
} 
película de Lubitsch Rosita (1923) o de The devil is a woman (1935) la adaptación de Josef von Sternberg de la novela de Pierre Louÿs, La femme et le pantin (1998) con Marlene Dietrich haciendo de rubia andaluza improbable. Esta película, según Marta García Carrión, fue:

El mayor escándalo de la década ya que "[...] Se desató una activa campaña en contra de la película, protestas estudiantiles incluidas en Madrid y Sevilla, encabezadas por Gil Robles que impulsó su retirada de las pantallas por considerarla un conjunto de tópicos y falsedades sobre España. [...] Se exigió de la Paramount que retirara completamente la película y quemara el negativo, volviendo a esgrimir la amenaza de vetar a la productora en España. (García Carrión, pp. 59-60)

Las diferencias lingüísticas y las incomprensiones entre alemanes y españoles son también fuentes de numerosos momentos humorísticos, empezando por la interpretación alemana de la película por una Penélope Cruz con acento español muy marcado y la risa que produce ver a una arquetípica folklórica andaluza hablar y cantar en alemán -esta comicidad siendo debida a un doble desfase : el desfase entre tópicos españoles y lengua alemana y el desfase temporal ya que hoy en día el público, incluso si nos es hispano, puede difícilmente admitir una convención que se aceptaba en los años 30. Las incomprensiones y las traducciones diplomáticas del intérprete son también otras tantas fuentes de quid pro quo y de gags basados en el desajuste entre lo que se dice y lo que se traduce.

El gran acierto de la película es la elección de la adopción de un sólo punto de vista hispano con situaciones y diálogos chistosos que se arraigan en la cultura española y en los que se puede percibir el humor de Rafael Azcona. Según Juan Antonio Ríos Carratalá, el famoso guionista español parte de la comicidad sainetesca ${ }^{10}$ añadiendo su propio humor a "esa misma tradición aportándole una mayor profundidad, una riqueza de lecturas que no encontramos en otras películas ${ }^{11}$ ". En La niña de tus ojos, este humor azconiano se percibe en particular en el tratamiento de la caracterización de cada miembro

\footnotetext{
${ }^{10}$ En su obra Lo sainetesco en el cine español, Juan Antonio Ríos Carratalá define los rasgos característicos del sainete. Muchos coinciden con la narración de La niña de tus ojos, como por ejemplo : una estructura coral, la utilización de estereotipos ya definidos, una galería de tipos, un ambientes populares, uso de regionalismos o localismos. Riós Carratalá, Juan Antonio, Lo sainetesco en el cine español, Publicaciones de la universidad de Alicante, 1997, pp. 20-22.

${ }^{11}$ Ríos Carratalá, Juan Antonio, El sainete y el cine español, Edición digital, Alicante, Biblioteca Virtual Miguel de Cervantes, 2003.

http://bib.cervantesvirtual.com/FichaObra.html?portal=0\&Ref=11313
} 
de la compañía de los cómicos españoles. En efecto, tanto el aspecto coral de la obra, el grupo de actores, unos individuos comunes y corrientes, antihéroes cada uno con sus debilidades - una es alcohólica, otra envidiosa, el galán Torralba un cobarde vanidoso- y que parecen más víctimas de la vida que protagonistas de su propio destino, como los diálogos chispeantes y los chistes jocosos -muchos alrededor del sexo o de la comida, verdadera obsesión de los protagonistas que llegan de la España paupérrima de la guerra civil- remiten al humor de Azcona (pensemos entre muchísimos en El cochecito (Marco Ferreri, 1960), El verdugo (Luis García Berlanga, 1963) o ¡Ay Carmela! (Carlos Saura, 1990) ${ }^{12}$. En efecto, a pesar de que el guionista siempre afirmaba que se ponía al servicio de los directores, "Soy como una criada que trato de servirle a los directores lo que me piden $^{13}$, , Fernando Trueba declara a la inversa: “ aunque a día de hoy se siga considerando al director el "autor" de una película -en vez del ejecutor, que es lo que realmente somos-, yo desafío a cualquier integrista de la "política de los autores" a imaginar qué sería la obra de Berlanga, Saura, García Sánchez o Trueba sin Azcona para que se le cure su momentánea ceguera. ${ }^{14,}$

La caracterización muy cuidada de los protagonistas los aleja de la caricatura y la película se burla con mucho cariño de la vanidad y de las debilidades de los actores cuando, por el contrario, ridiculiza cruelmente a los nazis. Anne E. Hardcastle apunta que esta caracterización implica una perspectiva de la historia ideológica de España "que 'olvida su pasado' fascista y presenta una sensibilidad moderna y democrática ${ }^{15}$ " . En efecto, cuando los nazis confunden a Julián, el galán de la película que a lo largo de la obra hace alarde de sus opiniones fascistas, con el extra judío, lo torturan y lo maltratan. En cuanto sus compañeros aclaran la confusión y que sale malherido de las cárceles nazis, se lamenta diciendo : “¡Con lo fascista que era!” o sea que el escarmiento parece haber dado sus frutos lo que significaría, según la autora estadounidense, que los españoles

\footnotetext{
${ }^{12}$ No hay que menospreciar sin embargo la labor de David Trueba en la elaboración del guión. Según su hermano, él y Rafael Azcona : "son los dos guionistas con los que mejor me he entendido siempre. He intentado que el trabajo no fuera un cóctel entre los dos. El problema es que, después de tanto tiempo y tantas versiones, no se puede decir de quién es cada cosa, quién puso ésta o aquella frase. La escritura en colaboración es así". Mora, Miguel, El País, 4/11/1998 http://elpais.com/diario/1998/11/04/cultura/910134010_850215.html

${ }^{13}$ Entrevista a Rafael Azcona. http://www.elmundo.es/especiales/2008/03/cultura/azcona/trueba.html

${ }^{14}$ Trueba, Fernando, "Trabajando con Rafael", Nosferatu, n $^{\circ} 33$, abril 200, p.55.

${ }^{15}$ Hardcastle, Anne E., "Representing Spanish identity through españolada in Fernando Trueba's The Girl of Your Dreams (La niña de tus ojos), op.cit., pp. 15-37.
} 
enfrentados con los verdaderos fascistas se darían cuenta y volverían a la razón. Esta opinión puede ponerse en tela de juicio ya que en el noticiario español ficticio que abre la película durante los títulos de crédito, asocia estrecha y claramente el bando nacionalista y el régimen nazi. En cambio, los cómicos se presentan más bien como pobres diablos que sólo intentan sobrevivir en la tormenta de la guerra civil y de la Alemania nazi. Señalemos que es también lo que ocurre a los protagonistas de la película de Carlos Saura ;Ay Carmela!, escrita por el director aragonés en colaboración con Rafael Azcona.

Un último elemento que por una parte arraiga la película en la tradición española y la enmarca también en un homenaje cinematográfico es que, en realidad, la obra no es una pura comedia sino más bien una tragicomedia.

Esta característica corresponde con una tradición muy enraizada en la tradición española ya que según Monique Martínez Thomas :

[...] la tradición española de la mezcla de géneros que empieza con La Celestina de Fernando de Rojas [...] plantea un problema no resuelto hasta hoy por los teóricos del teatro. Lope de Vega habla en su Arte nuevo de hacer comedia, de "lo trágico y lo cómico mezclado" y Ricardo de Turia declara en 1612: ninguna comedia de cuantas se representan en España lo es sino tragicomedia, que es un mixto formado de lo cómico y lo trágico ${ }^{16}$.

En La niña de tus ojos, al principio de la narración, la sucesión de gags y de diálogos chistosos dan al relato una clara tonalidad cómica e incluso la representación de la Noche de los Cristales Rotos aparece muy desrealizada, lo que le resta brutalidad y permite pues inscribir la película en el género de la comedia. Sin embargo, poco a poco, a medida de que los protagonistas van tomando consciencia de la violencia de la sociedad en la que se han metido, los momentos trágicos van alternando con los momentos cómicos. Momentos violentos o crueles se entrelazan pues con episodios divertidos o burlescos en la trama. Hasta el mismísimo director de la película, Blas Fontiveros, que al principio antepone la película a todo -incluso a su relación romántica con Macarena Granada a quien entrega a Goebbels-, se convierte en un héroe de Film noir ya que se sacrifica por la mujer a la que ama y la salva con su amante judío, dejándolos al pie de la escalera de un avión en un claro homenaje a la última secuencia de Casablanca (Michael Curtiz, 1942). Permanece detenido en Berlín mientras los otros miembros de la compañía vuelven a España y se deduce perfectamente que le puede esperar un final fatal.

${ }^{16}$ Martínez Thomas, Martine, Los herederos de Valle Inclán, ¿mito o realidad?, Murcia, Universidad de Murcia, 1997, p.75. 
El autor de Belle Époque tenía muy claro que quería sobre todo mezclar los géneros: "Creo que, al final, es una comedia que se va volviendo dramática por las circunstancias que rodean al equipo. Cada vez me gusta más jugar con lo romántico, lo cómico, lo trágico. Ya lo había hecho, pero ahora lo he llevado un poco más lejos. Al fin y al cabo, la vida es sólo un contraste continuo" ${ }^{17}$. Sin embargo, con este doble homenaje a la tradición hollywoodiense y a la tradición hispánica, el director madrileño confirma de manera magistral que también las películas de género y en particular las comedias, pueden ser obras comprometidas política y socialmente. Sus principales referencias hollywoodienses, Ernst Lubitsch y Billy Wilder, tuvieron que exiliarse frente a la amenaza nazi y sus películas denuncian a menudo los desarreglos de la sociedad. Según Jean-Marc Leveratto:

Ver al principio de este siglo XXI, To be or not to be, es reír espontáneamente de la sátira feroz de los Nazis que Lubitsch construye articulando "cómico de carácter" -la necedad satisfecha de sí misma del coronel SS Erhardt, interpretado por Sig Ruman- y el "cómico de situación", es decir la "rigidez de la idea fija" que hace totalmente imprevisible, y por consiguiente inhumana, las reacciones de estos nazis. [...] Comulgamos pues con la idea que expresa la película, cuya acción nos conduce a simpatizar con los resistentes que se niegan, arriesgando la vida, a someterse al nazismo $^{18}$.

La risa que produce la actitud inhumana de los nazis en la película de Fernando Trueba funciona de la misma manera: nos reímos del carácter "mecánico" de la conducta de los nazis ya que según Bergson "nos reímos cada vez que una persona nos da la impresión de ser una cosa"19 y percibimos entonces que constituye una amenaza para la sociedad. Por eso, el espectador de la película siente empatía por los cómicos, -que sus debilidades hacen aún más humanos- y rechaza a los Nazis que considera "inhumanos". La risa y la comedia contribuyen pues a vehicular una ideología democrática y a rescatar la memoria de los republicanos, dejando claras las afinidades ideológicas entre falangismo y nazismo.

\footnotetext{
${ }^{17}$ Mora, Miguel "Trueba considera que La niña de tus ojos es su película más difícil”, op.cit.

18 "Regarder, en ce début du XXIe siècle, To be or not to be, c'est rire spontanément de la satire féroce de Nazis que Lubitsch construit en articulant 'comique de caractère', -la bêtise satisfaite d'elle même du colonel SS Ehrardt, joué par Sig Ruman- et comique de situation, soi la 'raideur de l'idée fixe' qui rend parfaitement prévisibles, et donc inhumaines, les réactions de ces nazis. » Leveratto, Jean-Marc, Analyse d'une æeuvre : To be or not to be, Ernst Lubitsch, 1942.

19 "Nous rions toutes les fois qu'une personne nous donne l'impression d'un chose" Bergson, Henri, Le rire. Essai sur la signification du comique, p.414.
} 
Por otra parte, la recuperación de varias tradiciones españolas también se puede vincular con un compromiso político. Es el caso de la españolada que Fernando Trueba utiliza para su mise en abyme de la creación cinematográfica. Este género y estas canciones populares, que florecían antes de la guerra civil, fueron confiscados por el régimen franquista que se apropió del folclore andaluz. Salvando las distancias y con procesos creativos completamente distintos, se puede establecer un paralelo entre la obra de Trueba y la película de Basilio Martín Patino, Canciones para después de una guerra (1971), cuyo mecanismo complejo de montaje imagen/sonido pretende recuperar la cultura popular de las canciones populares confiscadas por el régimen. Por fin, el humor a menudo sainetesco de la película remite a una larga tradición española que también fue explotada por el cine disidente en los años cincuenta. La opera prima de Juan Antonio Bardem y Luis García Berlanga, Esa pareja feliz, es un buen ejemplo de ello -con construcción abismal, esta vez irónica, incluida al principio de la obra. Luis García Berlanga y Fernando Fernán Gómez ahondarían en sus obras posteriores en esta vena que también fue muy explotada por los directores o guionista afines al régimen tal como José Luis Sáenz de Heredia, Luis Marquina o Rafael Juan Salvia.

Con La niña de tus ojos, Fernando Trueba ha conseguido pues elaborar una obra divertidísima que es a la vez histórica, cinéfila, política y un homenaje a los clásicos, con elementos trágicos reuniendo el carácter universal de las películas hollywoodenses con lo particular de la tradición tragicómica española. Demuestra con esta obra magistral que diversión y género no están reñidos con el compromiso ni por supuesto con la autoría. Por el contrario, el humor permite descubrir muy crudamente el horror, denunciándolo, y conquista al espectador con unas herramientas tremendamente potentes.

\section{BIBLIOGRAFÍA}

Bergson, Henri, Le rire. Essai sur la signification du comique.

García Carrión, Marta, Sin Cinematografía no hay nación. Drama et identidad nacional española en la obra de Florián Rey, Zaragoza, Institución "Fernando el Católico.", p.49.

Hardcastle, Anne E., "Representing Spanish identity through españolada in Fernando Trueba's The Girl of Your Dreams (La niña de tus ojos), Film Criticism, Vol. 31, №3, (Spring 2007). 
Leveratto, Jean-Marc, Analyse d'une æuvre : To be or not to be, Ernst Lubitsch, 1942.

Martínez Thomas, Martine, Los herederos de Valle Inclán, ¿mito o realidad?, Murcia, Universidad de Murcia, 1997.

Mora, Miguel, "Trueba considera que La niña de tus ojos es su película más difícil” El País, 4 de noviembre de 1998.

http://elpais.com/diario/1998/11/04/cultura/910134010 850215.html. Última consulta: 15/12/2013.

Navarrete Cardero, José Luis, Historia de un género cinematográfico: La Españolada, Quiasmo Editorial, 2009.

Ríos Carratalá , Juan Antonio, Lo sainetesco en el cine español, Publicaciones de la universidad de Alicante, 1997.

Ríos Carratalá, Juan Antonio, El sainete y el cine español, Edición digital, Alicante, Biblioteca Virtual Miguel de Cervantes, 2003.

http://bib.cervantesvirtual.com/FichaObra.html?portal=0\&Ref=11313

Rodríguez Fuentes, Carmen, “ La realidad ficcionada en La niña de tus ojos de Fernando Trueba”, Actas del I congreso Internacional Latina de Comunicación Social, Universidad de La Laguna, SLCS, 2009.

Trueba, Fernando, “Trabajando con Rafael”, Nosferatu, n 33, abril 2000.

Yraola, Aitor, “"Misión españolista': Los camaradas Florián e Imperio con Hitler y el DR. Goebbels",

www.publicacions.ub.edu/.../cinema/.../art.yraola.pdf. Última consulta, 15/12/2013. 